University of Nebraska - Lincoln

DigitalCommons@University of Nebraska - Lincoln

$12-2007$

\title{
Response of phlebotomine sand flies to light-emitting diode- modified light traps in southern Egypt
}

\author{
D. F. Hoel \\ Emad Y. Fawaz \\ United States Navy Medical Research Unit \\ J.E Butler \\ University of Florida, butler@che.ufl.edu \\ N. Watany \\ United States Naval Medical Research Unit \\ S. S. El-Hossary \\ United States Naval Medical Research Unit \\ See next page for additional authors
}

Medical Entomology Collaborations, David.Hoel@med.navy.mil

Follow this and additional works at: https://digitalcommons.unl.edu/usnavyresearch

Part of the Operations Research, Systems Engineering and Industrial Engineering Commons

Hoel, D. F.; Fawaz, Emad Y.; Butler, J.E; Watany, N.; El-Hossary, S. S.; and Villinski, J., "Response of phlebotomine sand flies to light-emitting diode-modified light traps in southern Egypt" (2007). U.S. Navy Research. 24.

https://digitalcommons.unl.edu/usnavyresearch/24

This Article is brought to you for free and open access by the U.S. Department of Defense at DigitalCommons@University of Nebraska - Lincoln. It has been accepted for inclusion in U.S. Navy Research by an authorized administrator of DigitalCommons@University of Nebraska - Lincoln. 


\section{Authors}

D. F. Hoel, Emad Y. Fawaz, J.E Butler, N. Watany, S. S. El-Hossary, and J. Villinski 


\title{
Response of phlebotomine sand flies to light-emitting diode-modified light traps in southern Egypt
}

\author{
D.F. Hoel ${ }^{1}$, J.F. Butler ${ }^{2}$, E. Y. Fawaz ${ }^{1}$, N. Watany ${ }^{1}$, S.S. El-Hossary ${ }^{1}$, and J. Villinski ${ }^{1}$ \\ ${ }^{1}$ U.S. Naval Medical Research Unit No. 3, Cairo, Egypt
}

${ }^{2}$ Department of Entomology and Nematology, University of Florida, Institute of Food and Agricultural Sciences, Building 970, Hull Road, Gainesville, FL 32611, U.S.A.

Received 28 April 2007; Accepted 17 July 2007

\begin{abstract}
Centers For Disease Control and Prevention (CDC) light traps were modified for use with light-emitting diodes (LED) and compared against a control trap (incandescent light) to determine the effectiveness of blue, green, and red lights against standard incandescent light routinely used for sand fly surveillance. Light traps were baited with dry ice and rotated through a 4 x 4 Latin square design during May, June, and July, 2006. Trapping over 12 trap nights yielded a total of 2,298 sand flies in the village of Bahrif, $6 \mathrm{~km}$ north of Aswan on the east bank of the Nile River in southern Egypt. Phlebotomus papatasi comprised $94.4 \%$ of trap collections with five other species collected in small numbers. Over half $(55.13 \%)$ of all sand flies were collected from red light traps and significantly more sand flies $(P<0.05)$ were collected from red light traps than from blue, green, or incandescent light traps. Red light traps collected more than twice as many sand flies as control (incandescent) traps and $>4 \mathrm{x}$ more than blue and green light traps. Results indicate that LED red light is a more effective substitute for standard incandescent light when surveying in areas where P. papatasi is the predominant sand fly species. Each LED uses approximately $15 \%$ of the energy that a standard CDC lamp consumes, extending battery life and effective operating time of traps. Our prototype LED-modified traps performed well in this hot, arid environment with no trap failures. Journal of Vector Ecology 32 (2): 302-308. 2007.
\end{abstract}

Keyword Index: Light trap, color, diode, Phlebotomus papatasi, sand fly.

\section{INTRODUCTION}

Vision is a major component of several important aspects of biting fly ecology including appetitive flight, carbohydrate location, migration, dispersal, and oviposition site selection (Allan et al. 1987, Allan 1994, Snow 1971). Target size, shape, movement, contrast, and color are components of visual cues used by hematophagous insects for host location (Brown 1953, 1954). Target color is formed from reflected sunlight or can be provided from surface reflection of artificially transmitted light. Nocturnally active flies are often attracted to light of differing intensity and color; early recognition of this behavior led to the development of prototype New Jersey light traps (NJLT) during the 1920s for mosquito surveillance (Rudolfs 1922). The NJLT uses an incandescent light bulb (25 W) as a single and effective attractant for many mosquito species and is often the mainstay for routine mosquito surveillance. The need for smaller and more portable traps capable of operation in areas without alternating current electricity led to the development of CDC-type light traps (Sudia and Chamberlain 1962) which use incandescent light from a small incandescent lamp powered by $6 \mathrm{~V}$ batteries and are often supplemented with a carbon dioxide attractant.

Over the last 70 years, researchers have tested a large array of traps incorporating artificial light of different color, intensity, and/or frequency in attempts to enhance trap capture effectiveness (Breyev 1963, Service 1993,
Bidlingmayer 1994). Trap color (reflected light) and lamp color (transmitted light) have been among the most intensely studied of these visual cues in attempts to increase trap capture efficacy for a variety of mosquitoes and other biting flies (Barr et al. 1963, Service 1993). Trap color and contrast can be very important to diurnally active flies such as Glossina spp. and Aedes (Stegomyia) mosquitoes (Brown 1953, 1954, Browne and Bennett 1981). However, lamp color can play a role in attraction of nocturnally active flies not having the benefit of ambient light (Breyev 1963). Night biters are believed to be more capable of discriminating between shades of gray and recognizing contrast in dim light than day biters (Allan et al. 1987). The fact that many species of nocturnally active mosquitoes are attracted to artificial light is well known, although the reasons for this are not clear.

Light-emitting diodes (LEDs) have become a widely available and popular substitute for incandescent light over the past 15 years. Advantages of using LEDs over incandescent light bulbs include greatly reduced power consumption, cooler operating temperatures, extended operational life, less susceptibility to shock damage, compact size, and monochromatic light production in a wide variety of frequencies (colors). All these factors favor their use in mosquito light traps; especially those powered by batteries, as the four LEDs per trap that we used consumed approximately $80 \mathrm{ma} / \mathrm{h}$ per $\mathrm{h}(20 \mathrm{ma} / \mathrm{h}$ x four LEDs $)$ compared to a standard incandescent bulb (CM-47, J.W. 


\section{Report Documentation Page}

Form Approved

OMB No. 0704-0188

Public reporting burden for the collection of information is estimated to average 1 hour per response, including the time for reviewing instructions, searching existing data sources, gathering and maintaining the data needed, and completing and reviewing the collection of information. Send comments regarding this burden estimate or any other aspect of this collection of information,

including suggestions for reducing this burden, to Washington Headquarters Services, Directorate for Information Operations and Reports, 1215 Jefferson Davis Highway, Suite 1204, Arlington

VA 22202-4302. Respondents should be aware that notwithstanding any other provision of law, no person shall be subject to a penalty for failing to comply with a collection of information if it

does not display a currently valid OMB control number.

\begin{tabular}{|c|c|}
\hline $\begin{array}{l}\text { 1. REPORT DATE } \\
\text { APR } \mathbf{2 0 0 7}\end{array}$ & $\begin{array}{l}\text { 3. DATES COVERED } \\
\mathbf{0 0 - 0 0 - 2 0 0 7} \text { to 00-00-2007 }\end{array}$ \\
\hline \multirow{3}{*}{$\begin{array}{l}\text { 4. TITLE AND SUBTITLE } \\
\text { Response of phlebotomine sand flies to light-emitting diode-modified light } \\
\text { traps in southern Egypt }\end{array}$} & 5a. CONTRACT NUMBER \\
\hline & 5b. GRANT NUMBER \\
\hline & 5c. PROGRAM ELEMENT NUMBER \\
\hline \multirow[t]{3}{*}{ 6. AUTHOR(S) } & 5d. PROJECT NUMBER \\
\hline & 5e. TASK NUMBER \\
\hline & 5f. WORK UNIT NUMBER \\
\hline $\begin{array}{l}\text { 7. PERFORMING ORGANIZATION NAME(S) AND ADDRESS(ES) } \\
\text { U.S. Naval Medical Research Unit No. 3,Cairo, Egypt, }\end{array}$ & $\begin{array}{l}\text { 8. PERFORMING ORGANIZATION } \\
\text { REPORT NUMBER }\end{array}$ \\
\hline \multirow[t]{2}{*}{ 9. SPONSORING/MONITORING AGENCY NAME(S) AND ADDRESS(ES) } & 10. SPONSOR/MONITOR'S ACRONYM(S) \\
\hline & $\begin{array}{l}\text { 11. SPONSOR/MONITOR'S REPORT } \\
\text { NUMBER(S) }\end{array}$ \\
\hline
\end{tabular}

12. DISTRIBUTION/AVAILABILITY STATEMENT

Approved for public release; distribution unlimited

13. SUPPLEMENTARY NOTES

14. ABSTRACT

see report

15. SUBJECT TERMS

16. SECURITY CLASSIFICATION OF:

\begin{tabular}{c|c|c|}
$\begin{array}{c}\text { a. REPORT } \\
\text { unclassified }\end{array}$ & $\begin{array}{c}\text { b. ABSTRACT } \\
\text { unclassified }\end{array}$ & $\begin{array}{c}\text { c. THIS PAGE } \\
\text { unclassified }\end{array}$
\end{tabular}

17. LIMITATION OF ABSTRACT

Same as

Report (SAR)

\begin{tabular}{c|l}
$\begin{array}{c}\text { 18. NUMBER } \\
\text { OF PAGES } \\
\mathbf{7}\end{array}$ & 19a. NAME OF \\
& \\
& \\
\end{tabular}


Hock Company, Gainesville, FL) routinely used in CDCtype light traps that uses approximately $150 \mathrm{ma} / \mathrm{h}$. Lightemitting diodes have only recently been tested as substitutes for incandescent light in insect light traps (Burkett et al. 1998). All work thus far has focused on mosquito trapping.

The results of attempts to trap woodland mosquitoes in north Florida by Burkett et al. (1998) with LED-modified $\mathrm{CDC}$ traps were variable. They used incandescent light, no light, and traps supplied with four each blue, green, yellow, orange, red, or infrared LEDs mounted in two positions to produce reflected light (LEDs mounted on the lamp post facing the rain shield), and transmitted light (LEDs spaced $90^{\circ}$ around the diameter of the trap body, midway on the vertical axis, and facing outwards parallel to the ground). Results of these trials demonstrated that some species of Anopheles, Culex, Culiseta, Ochlerotatus, and Psorophora mosquitoes were attracted in larger numbers to particular colors over others. In such instances, blue or green light was usually favored, but light color had a significant effect on capture numbers, with incandescent light most often performing nearly as well as blue and green light and generally better than red, orange, or yellow light. Infrared light traps performed poorly. Related work by Burkett comparing blue and green light LED-modified CDC traps against control (incandescent light) traps in north Florida demonstrated that, with the exception of Culex (Melanoconion) spp., mosquitoes showed no preferences between incandescent, blue, or green light as either transmitted light or reflected light (Doug Burkett, personal communication). In that study, diodes pointed away from the trap housing were classified as transmitted light, light from diodes directed up towards aluminum rain shields, and thus reflected, was deemed reflected light. Burkett's work demonstrated, that in the majority of cases, woodland mosquitoes were more attracted to reflected light than to transmitted light, although trap totals were not significantly different. We reached the same conclusions in the Sinai Peninsula while collecting sand flies from LED-modified CDC light traps with LEDs directed away from traps (transmitted light) and from traps in which LED light was directed towards the aluminum rain shield (reflected light) during pilot trials in September, 2005. Our results led us to choose reflected light for subsequent field testing. We found no previous literature pertaining to the use of colored LEDs as attractants for field populations of sand flies. Our goal was to determine whether LEDs are effective substitutes for incandescent lamps used in batterypowered mosquito traps for sand fly surveillance, and if so, to determine the best color for medically important sand fly species.

\section{MATERIALS AND METHODS}

Our study was conducted six km north of Aswan, in the village of Bahrif, Aswan Governorate, Egypt, approximately $900 \mathrm{~km}$ south of Cairo. Subsistence farming in the Nile River Valley occurs in and around villages adjacent to both shores

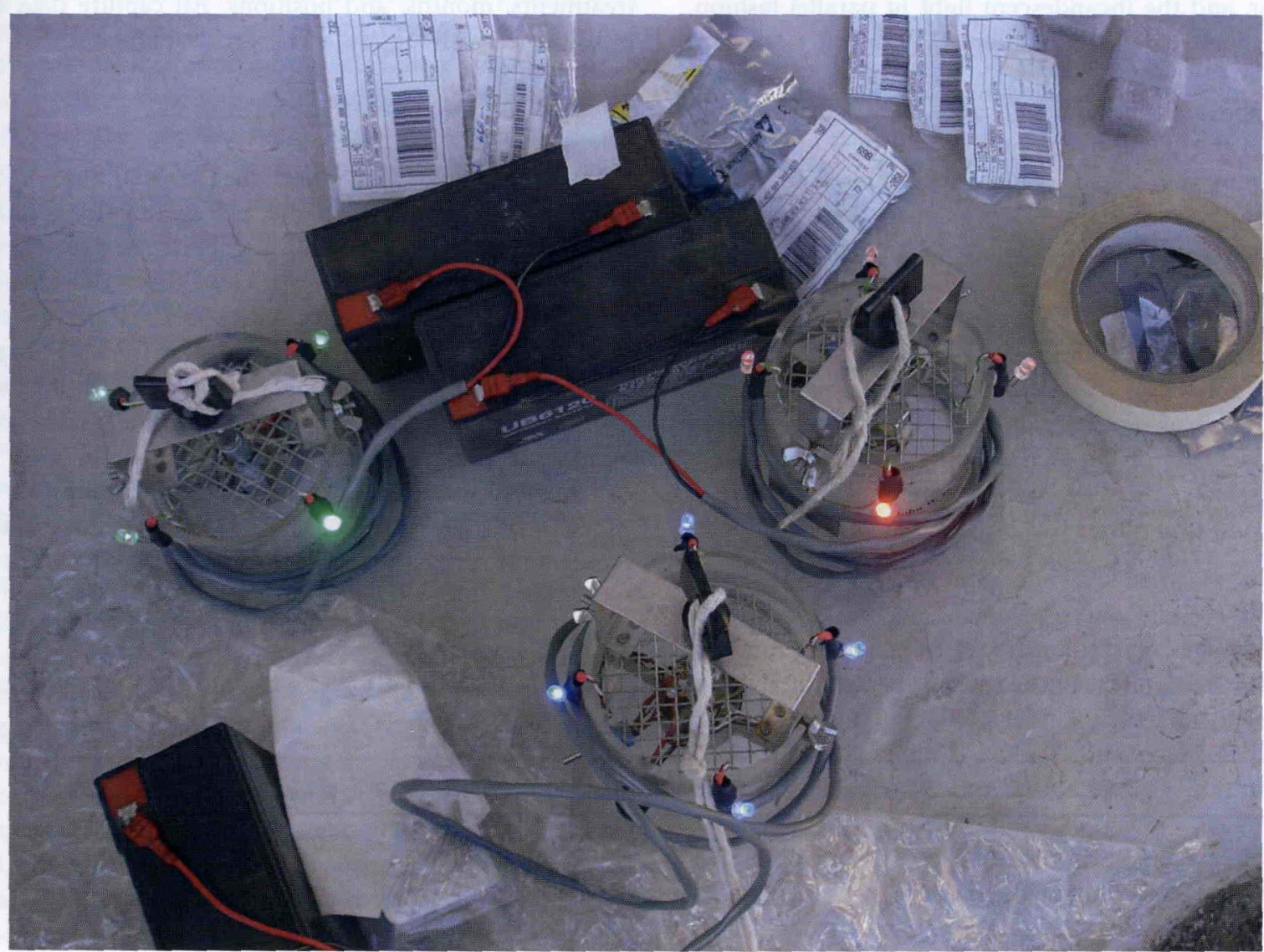

Figure 1. Light-emitting diode (LED)-modified CDC light traps (model 512, JW Hock Company, Gainesville, FL). Traps were designed to accommodate plug-in type LEDs to facilitate quick replacement or color change. 
of the river, as in Bahrif. These villages are typically cultivated in date palms (Phoenix dactylifera), mangoes (Mangifera indica), wheat (Triticum aestivum), corn (Zea mays), and clover (Trifolium spp.). Bahrif has a human population of approximately 400 and is stocked with domestic animals including cattle, dogs, and goats. The village is built from baked mud bricks and covered with kaolin clay to produce hardened, smooth wall surfaces, structures are one or two stories high and covered with thatch or brick roofs. Summers are very hot with daily temperatures typically ranging from $24^{\circ}$ to $45^{\circ} \mathrm{C}$; it seldom rains in Bahrif and the village received no rainfall during 2006 . This site was chosen for our study because of the large number of sand flies present in the area as observed by NAMRU-3 researchers over the previous 15 years and for the absence of Leishmania-infected flies. Trials were run in May, June, and July (2006) to take advantage of peak sand fly populations.

Blue, red, and green light LED-modified CDC light traps and one control trap using a standard CM-47, $6.3 \mathrm{~W}$ incandescent lamp were used in each of three $4 \times 4$ Latin square designed tests. John W. Hock model 512 traps (J.W. Hock Company, Gainesville, FL) were outfitted with a three-way toggle switch that allowed use of these traps with incandescent light, no light, or LED light (Figure 1). Four plug-in sockets were mounted around the top of the trap body cylinder, spaced $90^{\circ}$ apart and facing downward. Twenty gauge insulated electrical wire was routed between the toggle switch, LED plug in sockets, one $240 \mathrm{ohm}, 1 / 8$ $\mathrm{W}$ resistor, and the incandescent light in parallel fashion. Insulated Igloo dry-ice containers (J.W. Hock Company, Gainesville, FL) were loaded with c.a. $1 \mathrm{~kg}$ of dry ice and attached above the Model 512 traps in which the black plastic rain shield had been replaced with highly reflective flat aluminum rain shields commonly provided with other brands of CDC-type traps. Traps were set with the intake opening suspended approximately $45 \mathrm{~cm}$ above ground. All traps were activated $30 \mathrm{~min}$ before official sunset and collected between 6:30-7:00, shortly after official sunrise. Trap placement was randomized before each trial and traps were rotated in a clockwise fashion along a transect in which traps were spaced at least $50 \mathrm{~m}$ apart and not visible to each other from each trapping position. Fine mesh double ring collecting bags were used to ensure capture of sand flies and trap power was provided by $6 \mathrm{~V}, 12$ amperehour rechargeable gel cell batteries (Battery Wholesale
Distributors, Georgetown, TX).

The LEDs used in this study were obtained from Digi-Key Corporation (Thief River Falls, MN). Color, part number, wavelength, and millicandela (mcd) chosen for testing were: blue ( $\mathrm{P} 466-\mathrm{ND}, 470 \pm 30 \mathrm{~nm}, 650 \mathrm{mcd}$ ), green (67-1755-ND, $502 \pm 25 \mathrm{~nm}, 1,500 \mathrm{mcd})$, and red (67-1611$\mathrm{ND}, 660 \pm 30 \mathrm{~nm}, 1,800 \mathrm{mcd}$ ). These LEDs were $8.6 \mathrm{~mm}$ in length by $5.0 \mathrm{~mm}$ in diameter with rounded lens and viewing angles of $30^{\circ}$. These diodes were manufactured with two flexible wire leads that were bent upward $180^{\circ}$ from plug attachments to provide reflected light from aluminum rain shields. The positive lead was slightly longer than the negative lead, facilitating correct polarity determination with respect to the trap plug device. Diode leads could be bent in any direction to point light in a direct line-of-site fashion (transmitted light) or towards a close object (such as a surveillance trap rain shield) to provide reflected light.

On the morning following a collection night, nets were removed and placed into 50-quart ice chests (Coleman Company, Wichita, KS) on dry ice to kill sand flies. Sand flies were then removed with mechanical aspirators and stored in $75 \%$ ethyl alcohol until cleared, mounted, and identified to species using a key of Egyptian phlebotomine sand flies developed by Lane (1986). Trap collections were analyzed for month (trial), position, and treatment (light color) using a 3-way ANOVA (SAS Institute 2001). The Ryan-Einot-Gabriel-Welsh Multiple Range Test was used to delineate significant differences $(\alpha=0.05)$ between treatments, months, and positions. All capture data were transformed with $\log _{10}(n+1)$ prior to analysis.

\section{RESULTS}

We collected 2,298 sand flies over a three-month collecting period of four nights per month (for a total of 12 nights and 48 trap-nights). Six species of sand fly were collected; Phlebotomus papatasi was the most abundant species in the field and comprised $94.39 \%$ of the entire catch (2,169 adults). Other species collected included $P$. sergenti (1.31\%), Sergentomyia schwetzi (4.0\%), S. clydei $(0.17 \%)$, S. tiberiadis $(0.09 \%)$, and S. antennata $(0.04 \%)$. A summary of monthly catches by species is presented in Table 1 .

Analysis of data yielded highly significant results $(F=$ $10.62 ; \mathrm{df}=8,39 ; P<0.0001)$. Sand fly collections differed significantly among treatments $(F=17.67 ; \mathrm{df}=3,8 ; P<$

Table 1. Phlebotomine sand fly totals per month (trial) collected from CDC traps with and without light-emitting diodes, Bahrif, Egypt, 2006.

\begin{tabular}{ccccccc}
\hline Month & P. papatasi & P. sergenti & S. schwetzi & S. tiberiadis & S. clydei & S. antennata \\
\hline May & 485 & 10 & 24 & 1 & 0 & 0 \\
June & 858 & 11 & 46 & 1 & 2 & 0 \\
July & 826 & 9 & 22 & 0 & 2 & 1 \\
Total & 2169 & 30 & 92 & 2 & 4 & 1 \\
\hline
\end{tabular}


Table 2. Treatment totals by trial with means ( \pm SEM) of all sand flies collected from light-emitting diode-modified traps over three trials with four treatments. Means followed by the same letter are not significantly different (Ryan-Einot-GabrielWelsh Multiple Range Test; $P<0.05$ ). $\mathbf{n}=12$ trap nights.

\begin{tabular}{cccccc}
\hline Treatment & Trial 1 & Trial 2 & Trial 3 & Total & Mean ( \pm SEM) \\
\hline Red & 304 & 486 & 477 & 1267 & $105.58 \pm 10.26 \mathrm{a}$ \\
Control & 73 & 192 & 249 & 514 & $42.83 \pm 11.50 \mathrm{~b}$ \\
Blue & 113 & 100 & 56 & 269 & $22.42 \pm 4.25 \mathrm{bc}$ \\
Green & 30 & 140 & 78 & 248 & $20.67 \pm 5.81 \mathrm{c}$ \\
Total & 520 & 918 & 860 & 2298 & \\
\hline
\end{tabular}

$0.0001)$, collection positions $(F=6.53 ; \mathrm{df}=3,8 ; P=$ $0.0011)$, and trials $(F=6.19 ; \mathrm{df}=2,8 ; P=0.0046)$. Sand flies strongly preferred red light to all other treatments, in fact, more than half of all sand flies were captured in red light-baited traps (55.13\%). The mean and standard error of the number of flies collected during the study for each of the four treatments were $105.58 \pm 10.26$ (red), $42.83 \pm$ 11.50 (incandescent), $22.42 \pm 4.25$ (blue), and $20.67 \pm 5.81$ (green) (Table 2). Because almost $95 \%$ of the trap capture was $P$. papatasi, similar results were seen with this medically important species (red $102.50 \pm 10.01$, incandescent 39.50 \pm 11.19 , blue $20.00 \pm 3.81$, green $18.75 \pm 5.27$; Table 3). Multiple comparison analysis demonstrated that the red light trap caught significantly more sand flies than any other treatment. CDC trap totals were not significantly different from blue trap totals but were significantly higher than green trap totals. Of the four collection positions, two were located adjacent to living quarters (one site was a dry, dusty animal shelter on the outside wall of a local residence) and the other two were set on opposite sides of an irrigated field near the first two sites. Those traps hung at the drier positions caught significantly more $(P=0.0011)$ sand flies than did the other two set by the irrigated field. Trials were also significantly different $(P=0.0046)$, with the majority of sand flies caught in June and July as compared to May (Table 1).

Results of treatment, trial, and position effect on species capture is presented in Table 3. Phlebotomus papatasi trapping results and statistical outcomes did not differ from overall results as this species accounted for $94.39 \%$ of the total take. Treatment (light color) was highly significant ( $F=$ $19.12 ; \mathrm{df}=3 ; P<0.0001)$ as was collection position $(F=7.08$; $\mathrm{df}=3 ; P=0.0007)$ and trial (month) $(F=5.92 ; \mathrm{df}=2 ; P=$ 0.0057 ). Likewise, multiple comparison results were similar, with red light traps capturing significantly more sand flies than other treatments and $\mathrm{CDC}$ traps catching significantly more sand flies than green light traps, and more, but not significantly more, than blue light traps. Female $P$. papatasi comprised $56.20 \%$ of the total $P$. papatasi trap capture from all treatments $(1,219$ of 2,169 adults), while female $P$. papatasi collected from red light-baited traps accounted for $53.74 \%(661$ of 1,230$)$ of all $P$. papatasi collected from those traps. With respect to the other five species of sand flies, no colored light preference was seen in any of them. We note here that their numbers were very small, especially in the case of S. tiberiadis, S. clydei, and S. antennata, which were too small for meaningful analysis $(2,4$, and 1 sand fly(s) collected, respectively).

\section{DISCUSSION}

Our study showed that $P$. papatasi sand flies in southern Egypt were attracted in significantly higher numbers to red light of a specific frequency $(660 \mathrm{~nm})$ than to incandescent light routinely used in CDC-type mosquito surveillance traps or to blue $(470 \mathrm{~nm})$ and green $(502 \mathrm{~nm})$ light produced from like diodes. Our findings that over half of all sand flies (> 55\%) preferred red light-baited traps to all other treatments and that red light attracted almost 2.5 times as many sand flies as did the next best treatment (incandescent light) was highly unexpected considering that most nocturnally active mosquitoes show preferences to blue, green, and incandescent light (Lehane 1991). We found no published literature concerning light preferences of phlebotomine sand flies and thus suspected that they would respond strongly to blue and green light as do mosquitoes (Burkett et al. 1998)

It has long been known that many nocturnally-active hematophagous insects are attracted to light, although the reasons for this are not clearly understood (Allan et al. 1987). Color produced from reflected sunlight is probably well-perceived in diurnal insects, but it is thought that nocturnally active host seekers such as mosquitoes are more capable of distinguishing shapes, contrast, and shades of gray and less capable of distinguishing color (Allan et al. 1987, Allan 1994). Simuliids, stable flies, tsetse flies, face flies, and horn flies are all are day-biting insects and visual trapping strategies rely on trap color, color contrast, shape, and size; artificial colored light is not particularly attractive to these biting flies or to diurnally active mosquitoes such as Aedes aegypti, Ae. albopictus, or Wyeomyia species (Bidlingmayer 1994, Wood and Wright 1968). Nevertheless, many nocturnally active blood feeders do show a preference for different colored artificial light; the most intensive investigative efforts have been directed at Culicids due to their primary importance as nuisance pests and disease vectors (Service 1993). Field and laboratory investigations into mosquito response to artificial light has shown, in large part, a bimodal spectral sensitivity to light in the ultravioletblue and green light spectrum, especially in mosquitoes (Lehane 1991, Muir et al. 1992, Allan 1994, Burkett et al. 1998). 
Mosquitoes respond to lights of various color, hues, intensities, and contrasts. Reflected sunlight, which imparts color to objects such as traps and cloth, has been studied in detail with respect to target attraction. Brett (1938) found that Aedes aegypti landed most frequently on black and red clothing while avoiding blue clothing and light khaki. Brown (1954) found that Canadian woodland species, mostly Aedes mosquitoes, preferred darker-colored cloth in the order of black $>$ red $>$ blue $>$ brown $>$ green $>$ white $>$ yellow. He concluded, as did Brett (1938), that these mosquitoes were attracted to colored surfaces with low reflectivity, and that some colors were enhanced by color contrast, such as red cloth against a green forest background. Conflicting results were obtained by Gilbert and Gouck (1957) in that Ae. taeniorhynchus, Ae. aegypti, and Ae. sollicitans preferred lighter-colored surfaces using reflected light of equal intensity instead of darker, low reflectance surfaces. These conflicting results may have been the result of differing spectral frequencies generated from targets to form visible color; spectral data was missing from all of these experiments so that while a particular color such as green may have attracted a large number of mosquitoes, it was not known whether they were attracted to a wavelength of light in the green light range of the spectrum $(\sim 500 \mathrm{~nm})$ or to a blend of light such as blue $(450 \mathrm{~nm})$ and yellow light $(550 \mathrm{~nm})$ that gives an appearance of green color. Attractancy studies with monochromatic light produced from LEDs have just recently begun and may possibly negate the confounding effects due to an array of spectral frequencies produced by artificial light generated from an incandescent source or a mix of several frequencies produced from painted lamps.

Our findings that $P$. papatasi prefers red light over incandescent, blue, or green light agrees with earlier findings that certain mosquito species also have colored light preferences. Ali et al. (1989) used enamel-painted lamps of light of six different colors (white, yellow, green, orange, blue, and red) and three wattages (intensities) to collect woodland mosquitoes in Florida. They found that five predominate species (Psorophora columbiae, Ps. ciliata, Culex salinarius, $C x$. nigripalpus, and $C x$. erraticus) were much more strongly affected by color than by light intensity. Blue was most attractive overall, followed by green and red light. Spectral composition of the light produced from the lamps was not given. In contrast, Gjullin et al. (1973) determined that male Ae. sierrensis, $C x$. quinquefasciatus, and $C x$. tarsalis were most strongly attracted to red light over green, blue, orange, or white light; lamps were dipped in ceramic paint and no spectral frequencies were given in this study. Females of these species preferred red light $(C x$, tarsalis) and green light ( $C x$. quinquefasciatus) to other colors. Males and females were collected in larger numbers in traps set with $7.5 \mathrm{~W}$ lamps than those set with $40 \mathrm{~W}$ lamps. These results tended to show that red light was most attractive to male mosquitoes and that lower intensity light produced by red lamps positively influenced trap capture. Barr et al. (1963) used several colored light bulbs of different intensities to capture California rice field mosquitoes (Anopheles and Aedes species) and concluded that color had little effect on 
trap capture but that light intensity played a significant role with higher intensity light (100 W lamps) more attractive than lower intensity light ( $60 \mathrm{~W}$ and $25 \mathrm{~W}$ lamps). Breyev (1963) collected significantly more Ae. vexans with one 220 $\mathrm{W}$ mercury lamp than with two $109 \mathrm{~W}$ incandescent lamps and more Aedes and Anopheles mosquitoes with mercury lamps than with incandescent lamps. He found that the high intensity $220 \mathrm{~W}$ mercury lamp was more attractive than the $109 \mathrm{~W}$ incandescent lamp and found that mercury vapor lamps produced much less light in the red spectrum than the incandescent light, noting that many insects are insensitive to red spectrum frequencies. The result of all four studies is that confounding information is given with respect to mosquito preference for light color and intensity. Thus, light color and intensity are shown to affect trap attractiveness, and although mosquitoes appear able to discern color and in cases prefer some colors to others (Brett 1938, Gilbert and Gouck 1957, Browne and Bennett 1981), these varying outcomes indicate that the spectrum of light produced by painted lamps probably differs due to component differences in the composition of various paints, thus yielding dissimilar spectral arrays and confounding our understanding of the color preferences of mosquitoes.

Light-emitting diodes offer a solution to the color preference problem: they transmit light at very specific frequencies within extremely narrow spectral ranges, eliminating the question of color attractiveness due to mixed frequencies. Nocturnally active phlebotomine sand flies respond well to CDC-type light traps which are commonly used for surveillance in connection with ecological studies and control efforts (Service 1993), but nothing is known of their preferences for colored light. Only one study has been performed on a New World sand fly (Lutzomyia longipalpis) measuring spectral sensitivity with an electroretinogram (Mellor et al. 1996). Responses in male and female $L$. longipalpis exposed to a range of wavelengths in the color spectrum found that both sexes responded maximally to ultraviolet light $(340 \mathrm{~nm})$ with a secondary peak in the blue-green-yellow region between 520 and $546 \mathrm{~nm}$.

Our findings were unexpected as it has been shown, at least with mosquitoes, that blue and green light is often more attractive than was light in the yellow-orange and red regions of the visible spectrum (Burkett et al. 1998). Clearly, P. papatasi was highly attracted to monochromatic red light; in these trials, $660 \mathrm{~nm}$ red light-baited traps performed significantly better $(P<0.05)$ than multi-spectrum light (incandescent light), blue light $(470 \mathrm{~nm})$, or green light $(502 \mathrm{~nm}$ ). Of the 1,230 adult $P$. papatasi captured in red light-baited traps, 661 (53.74\%) were females and 569 were males, indicating similar spectral sensitivities between sexes as seen with L. longipalpis. It is possible that the high intensity red light LED (1,800 mcd) was favored over the lower intensity blue light LED $(650 \mathrm{mcd})$ due solely to superior luminosity, however, the green light LED was rated at $1,500 \mathrm{mcd}$ and was thus very close to the intensity of the red light $\pm 17 \%$ ), although it captured the least number of sand flies. Interestingly, 5,845 mosquitoes from three genera (Anopheles, Culex, and Aedes) were trapped concurrently with sand flies during these trials. Order of effectiveness was green $>$ incandescent $>$ blue $>$ red light, following a documented trend in mosquitoes for attraction to light of shorter wavelengths (UV/blue and green) as seen in Florida woodland mosquitoes with both incandescent- and diodegenerated light (Burkett et al. 1998). Thus, we assume that $P$. papatasi was responding more strongly to light color than to light intensity. A second possible explanation might be due to our use of reflected light (off of aluminum rain shields) as opposed to transmitted light (direct line of sight). Background contrast produced from this reflected light may have triggered a more intense attraction response from sand flies compared to transmitted light which is not scattered as reflected light and is transmitted in a $30^{\circ}$ arc, reducing visual contrast and target size.

Of the remaining five sand flies species collected, no significant differences were noted in treatment, position, or trial, with the exception of Sergentomyia schwetzi, which was collected most often in the two dry positions over wet positions (Table 3). However, capture totals were so small (Table 1) that results other than those obtained for $P$. papatasi were deemed irrelevant. More work is needed to determine optimal color preferences of medically important sand flies as this work presents preliminary evidence that a strong preference is held for red light. Spectral sensitivities need to be determined in $P$. papatasi using electroretinograms to determine whether their attraction to the red light LED was due to the flys' sensitivity to light of $660 \mathrm{~nm}$ or the higher luminosity (and background contrast) produced by this particular LED (at 1,800 mcd, higher than blue or green LEDs). Regardless of the reason for the outcome obtained in these trials, it is clear that this particular red LED is superior to the standard incandescent light frequently used in CDC light traps to survey $P$. papatasi sand flies when used as reflected light. A range of microhabitats need to be tested, especially in the Saharan Desert of northern Africa, the arid sahel-savannah regions region just below the Saharan Desert, and other desert riverine ecosystems common in Leishmania transmission foci in Africa and southwest Asia. Results of this study provide the impetus for further field studies by demonstrating that medically important sand fly species such as $P$. papatasi might be more effectively collected in traps baited with light of specific color.

\section{Acknowledgments}

We thank Miss Nadal Mostafa from the Enteric Disease Research Program, U.S. Naval Medical Research Unit No. 3 , for her help with the statistical analysis for this project. Special thanks to Ranya Kaldas, NAMRU-3, for her assistance with sand fly processing and identification. Thanks to Dr. H. Hanafi for field site selection and coordination with Bahrif village officials. We also thank Maria F. Badra from the Vector Biology Research Program, NAMRU-3, for her help with the final preparation of the manuscript. This work was supported by the U.S. Naval Medical Research Center, Bethesda, MD work unit No. U0009 04 N3. The opinions and assertions contained herein are the private views of the 
authors and are not to be construed as official or reflecting the views of the Department of the Navy, Department of Defense, or the United States Government.

Authors from NAMRU-3 are military service members (or employees of the U.S. Government). This work was prepared as part of official duties. Title 17 U.S.C. $\$ 105$ provides that 'Copyright protection under this title is not available for any work of the United States Government.' Title 17 U.S.C. $\$ 101$ defines a U.S. Government work as a work prepared by a military service member or employee of the U.S. Government as part of that person's official duties.

\section{REFERENCES CITED}

Ali, A., J.K. Nayar, J.W. Knight, and B.H. Stanley. 1989. Attraction of Florida mosquitoes (Diptera: Culicidae) to artificial light in the field. Proc. Pap. 57 ${ }^{\text {th }}$ Annu. Conf. Calif. Mosq. Vect. Contr. Assoc. pp. 82-88.

Allan, S.A. 1994. Physics of mosquito vision - an overview. J. Am. Mosq. Contr. Assoc. 10: 266-271.

Allan, S.A., J.F. Day, and J.D. Edman. 1987. Visual ecology of biting flies. Annu. Rev. Entomol. 32: 297-316.

Barr, A.R., T.A. Smith, M.M. Boreham, and K.E. White. 1963. Evaluation of some factors affecting the efficiency of light traps for collecting mosquitoes. J. Econ. Entomol. 56: 123-127.

Bidlingmayer, W.L. 1994. How mosquitoes see traps: role of visual responses. J. Am. Mosq. Contr. Assoc. 10: 272 279 .

Brett, G.A. 1938. On the relative attractiveness to Aedes aegypti of certain coloured cloths. Trans. R. Soc. Trop. Med. Hyg. 32: 113-124.

Breyev, K.A. 1963. The effect of various light sources on the numbers and species of blood-sucking mosquitoes (Diptera: Culicidae) collected in light traps. Entomol. Rev. 42: 155-168.

Brown, A.W.A. 1953. Studies of the responses of the female Aedes mosquito. Part V. The role of visual factors. Bull. Entomol. Res. 44: 567-574.

Brown, A.W.A. 1954. Studies on the responses of the female Aedes mosquito. Part VI. The attractiveness of coloured cloths and Canadian species. Bull. Entomol. Res. 45: 67-78.
Browne, S.M. and G.F. Bennett. 1981. Response of mosquitoes (Diptera: Culicidae) to visual stimuli. J Med. Entomol. 18: 505-521.

Burkett, D.A., J.F. Butler, and D.L. Kline. 1998. Field evaluation of colored light-emitting diodes as attractants for woodland mosquitoes and other Diptera in north central Florida. J. Am. Mosq. Contr. Assoc. 14 186-195.

Gilbert, I.H. and H.K. Gouck. 1957. Influence of surface color on mosquito landing rates. J. Econ. Entomol. 50: 678-680.

Gjullin, C.M., D.G. Brandl, and J.J. O'Grady. 1973. The effect of colored lights and other factors on the numbers of Culex pipiens quinquefasciatus, $C x$. tarsalis and Aedes sierrensis entering light traps. Mosq. News 33:67-71.

Lane, R.P. 1986. The sand flies of Egypt (Diptera: Phlebotominae). Bull. Br. Mus. (Nat. Hist.) (Entomol.) 52: 1-35.

Lehane, M.J. 1991. Biology of Blood-Sucking Insects. Chapman and Hall, London. 288 pp.

Mellor, H.E., J.G.C. Hamilton, and M. Anderson. 1996. Spectral sensitivity in the eyes of male and female Lutzomyia longipalpis sandflies. Med. Vet. Entomol. 10: 372-374.

Muir, L.E., M.J. Thorne, and D.H. Kay. 1992. Aedes aegypti (Diptera: Culicidae) vision: spectral sensitivity and other perceptual parameters of the female eye. J. Med. Entomol. 29: 278-281.

Rudolfs, W. 1922. Chemotropism of mosquitoes. Bull. N.J Agric. Exp. Station, No. 367.23 pp.

SAS Institute. 2001. SAS/STAT user's manual, ver. 8.2. SAS Institute, Cary, N.C.

Service, M.W. 1993. Mosquito Ecology: Field Sampling Methods. Elsevier Applied Science. London. 988 pp.

Snow, F.W. 1971. The spectral sensitivity of Aedes aegypti (L.) at oviposition. Bull. Entomol. Res. 60: 863-696.

Sudia, W.D. and R.W. Chamberlain. 1962. Battery-operated light trap, an improved model. Mosq. News 22: 126129.

Wood, P.W. and R.H. Wright. 1968. Some responses of flying Aedes aegypti to visual stimuli. Canad. Entomol. 100: 504-513. 